\title{
EEG response to hyperventilation in patients with CNS disorder
}

\author{
Irma Khachidze ${ }^{1-3 *}$, Gugushvili $\mathrm{M}^{1}$, Inasaridze $\mathrm{K}^{1}$ and Advadze $\mathrm{M}^{2}$ \\ ${ }^{1}$ I. Beritashvili Center of Experimental Biomedicine, Tbilisi, Georgia \\ ${ }^{2}$ SEU University, Tbilisi, Georgia \\ ${ }^{3}$ Caucasus University, Georgia
}

\begin{abstract}
The mechanism of EEG (electroencephalography) alterations caused by forced breathing (hyperventilation test during functional loading) cause of high amplitude slow wave activity (paroxysmal synchronization) and development of epileptiform discharge has not been fully clarified. Different types of pathologic EEG reactions to hyperventilation hamper their interpretation, while the study of these phenomena is still of current interest. The goal of the investigation was to study and describe the EEG response to hyperventilation according to onset time of reaction and the pathological type of EEG. 2186 patients, who applied to D. Tatishvili Medical Center for examination, were recruited according to the EEG response to hyperventilation Based on the analysis of the results, 3 types of pathological EEG reactions/responses (PERH) (which have been revealed predominantly at the first minute of functional loading $(\mathrm{P}<0,05)$. The background rhythm of the EEG was restored within 2 and /or more minutes after the termination of loading. In 985 subjects 3 types of PERH have been revealed: First type of EEG reaction represents disorganization of the baseline rhythm, without paroxysmal reaction. Second type of EEG reaction reveal generalized, high-amplitude, monomorphic/polymorphic slow-wave paroxysmal discharges without epileptiform activity. Thirst type of EEG reaction reflects the epileptiform activity with and without generalized paroxysmal discharge. The EEG changes based on hyperventilation are linked to hypocapnia and concurrent acute alkalosis. It should be noted that partial pressure of carbon dioxide reduces to a minimum 1.5-2 minutes after hyperventilation, while pathologic changes in the EEG (paroxysmal EEG synchronization and/or generalized epileptiform discharges) are observed at the beginning of forced breathing. Such time incompatibility leads to search of alternative mechanisms that could more adequately explain the abovementioned phenomenon. We hypothesize to consider set of views developed by "hormesis theory". Hyperventilation causes a mild stress; which induces the appearance of PERH at the beginning of forced breathing
\end{abstract}

\section{Introduction}

The experience of modern medical practice has shown that, regardless of the intensive development and introduction of neuroimaging methods, electroencephalography (EEG) remains important. It is one of the most widely used methods of instrumental diagnostics of the CNS functional state in clinical and scientific studies [1-3]. EEG has proved to be more reliable (compared to the neuroimaging methods) in the diagnosis of epilepsy as well as of ischemic, degenerative, and inflammatory diseases of the brain (e.g. encephalopathy). It is also important that this method gives the possibility to evaluate the treatment efficacy in EEG- documented epilepsy and encephalopathy $[4,5]$. According to the International Guidelines, the procedure of EEG recording involves both the background activity and functional testing (photo-stimulation and hyperventilation). One of the most mandatory loads in clinical encephalography is the hyperventilation test involving the forced breathing for $3 \mathrm{~min}[6,7]$ or $3-5 \mathrm{~min}$. [8,9]. In healthy subjects this procedure causes a diffuse deceleration of the basic rhythm on the EEG $[10,11]$. In the patients with epilepsy, especially in those with absence seizures, hyperventilation provokes generalized epileptiform discharges [2,10]

The mechanism accounting for the origin of the changes in the EEG caused by hyperventilation, in particular, high amplitude slow wave activity (paroxysmal synchronization), has not been fully identified until now. Consequently, the existing conclusions concerning the influence of hyperventilation on the bioelectrical activity of the cerebral cortex are controversial. According to some authors [11-13], the cause of slow wave occurrence is the impairment of cerebral circulation due to hypocapnia and associated acute alkalosis, which leads to an inadequate oxygen and glucose supply to the brain. Other authors think that hyperventilation affects the brain potential both in humoral and reflex ways by means of the of blood vessel chemoreceptors [14], which causes reticular deactivation of the brain stem. This, in turn, leads to the modulating influence on the cerebral cortex $[11,12]$. Based on the literature, the hyperventilation test exhibits the changes in the EEG from the first minutes of recording $[11,12]$, while the aforementioned alterations regarding hypocapnia develop and reach the peak later [15-17]. Such incompatibility in time of the characteristics of the phenomena considered makes it necessary to search for alternative mechanisms that more adequately explain the deceleration of the EEG basic rhythm from the first minutes of hyperventilation and the causes of enhanced epileptogenesis. The aim of the investigation is to study and describe the EEG response to hyperventilation according to the reaction onset time and the type of pathologic EEG. Based on all of the above, the goal of the study is:

${ }^{\star}$ Correspondence to: Irma Khachidze, I. Beritashvili Center of Experimental Biomedicine; Tbilisi, Georgia, Tel: +995599327268; E-mail: irmakha@yahoo.com

Key words: electroencephalography, hyperventilation, epileptogenesis

Received: February 15, 2020; Accepted: February 26, 2020; Published: February 28, 2020 
1. Description and account of the reaction developed in response to hyperventilation.

2. Distribution of subjects with the reaction to hyperventilation into groups according to gender and age.

3. Determination of the reaction time (reaction at 1st, 2 nd, and 3 rd minute) in different age groups.

\section{Methods}

2186 patients, 1139 females and 1047 males aged 3 to 51 years, who applied to D. Tatishvili Medical Center for examination in 2009-2014, were recruited according to the EEG response to hyperventilation. The control group consisted of 1201 participants whose EEG reaction/response to hyperventilation was within the normal range while the number of those with pathologic EEG reaction/response to hyperventilation (PERH) was 985. The subjects with PERH were subdivided into the following age groups: 3-6, 7-12, 13-18, 19-30, 31-50, 50 and over years. The participants under study had different functional disorders of the CNS (headache, fatigue, attention-deficit disorder, drowsiness sleep disorders, unstable arterial pressure, encephalopathy, epilepsy, ADHD etc.)

The study was conducted in a screened, soundproof room at a temperature of $22^{\circ} \mathrm{C}$ in a state of calm sleep at one and the same time of the day (11 am-1 pm). The first EEG recording was carried out with the purpose of estimating the background activity with closed eyes which lasted for 5 minutes, then with open eyes $(5 \mathrm{~min})$ and again with closed eyes ( $5 \mathrm{~min}$ ). Hyperventilation lasted for 3 minutes, while breath holding (15-25 sec.) was done after the cessation of hyperventilation. The duration of EEG recording was 25-35 minutes.

After performing the Fourier transform, the EEG frequency component analysis was done within the following range: delta (0.5-4.0 $\mathrm{Hz})$, theta-1 $(4.0-6.0 \mathrm{~Hz})$, theta- $2(6.0-8.0 \mathrm{~Hz})$, alpha $(8.0-13 \mathrm{~Hz})$, beta$1(13-24 \mathrm{~Hz})$, beta-2 $(-50.8 \mathrm{~Hz})$. EEG recordings were performed using 24-32 channel computer electroencephalograph" ENCEPHALAN MEDICOM", with electrode location according to the International System 10-20, amplifier conductivity range $0.5-100 \mathrm{~Hz}$, filtration frequency $50 \mathrm{~Hz}$. the outputs being $3 \mathrm{db}$ down at these frequencies. The signals from each input electrode were digitized with sampling rate of $256 \mathrm{~Hz}$ with the resolution of 12 bits. Electrode $(\mathrm{Ag} / \mathrm{AgCl})$ specific resistance was $<5 \mathrm{KOhm}$ and $>1 \mathrm{KOhm}$ for all electrodes. EEG was stored on a hard disk for off-line analysis.

The reliability (authenticity) of the results was estimated using the SPSS 20.0 program for statistical processing.

\section{Results}

Based on the analysis of the data obtained, pathologic reaction to hyperventilation (PERH) was revealed in 985 subjects, which made up $45 \%$ of the total number of subject (2186). The distribution of the subjects according to the numerical and percentage indices into different age (3-6, 7-12, 13-18, 19-30, 31-50, 50 and over years) (Figure 1, Table 1) and gender (553 females and 432 males) (Figure 2, Table 2) groups are shown in tables and diagrams.

The manifestation of pathological reaction to hyperventilation (PERH) in time, implying the time point of the reaction occurrence, 1st, 2nd, 3rd minute, is shown in the tables and diagrams (Figure 3, Table 3). It should be noted that (PERH) is observed at 1st, 2 nd, and 3rd minutes of the forced breathing onset. Figure 3 shows that at the 1st minute of hyperventilation PERH is revealed (in numerical and

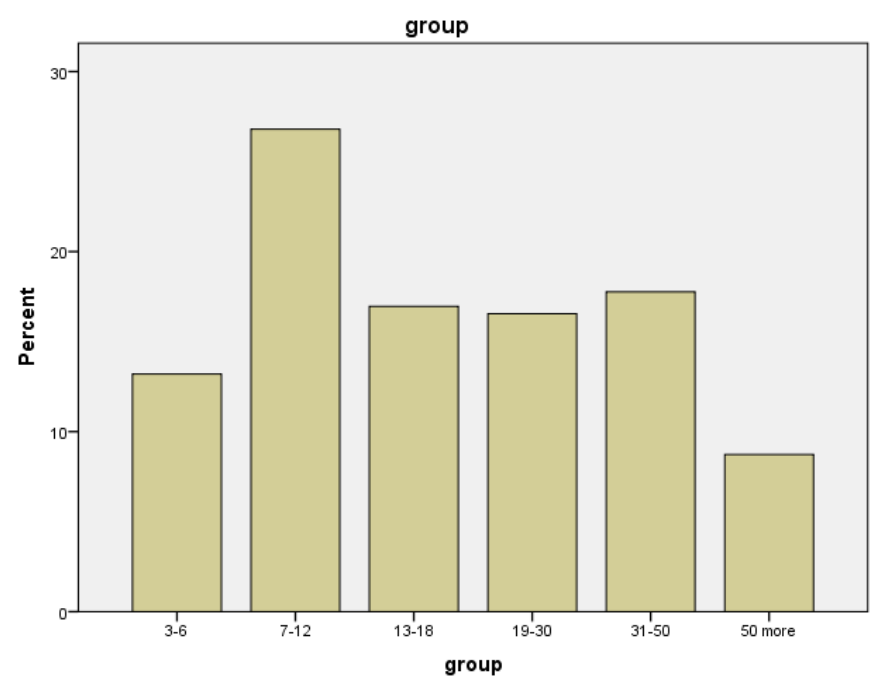

Figure 1. Quantitative and percentage data of individuals with pathological EEG-reactions on hyperventilation $(\mathrm{PERH})$ in different age groups

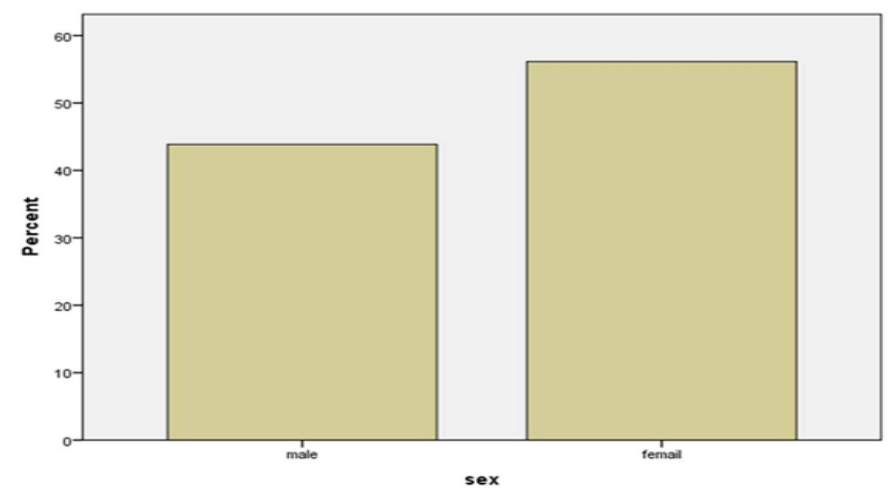

Figure 2. Quantitative and percentage data of subjects with PERH according to gender

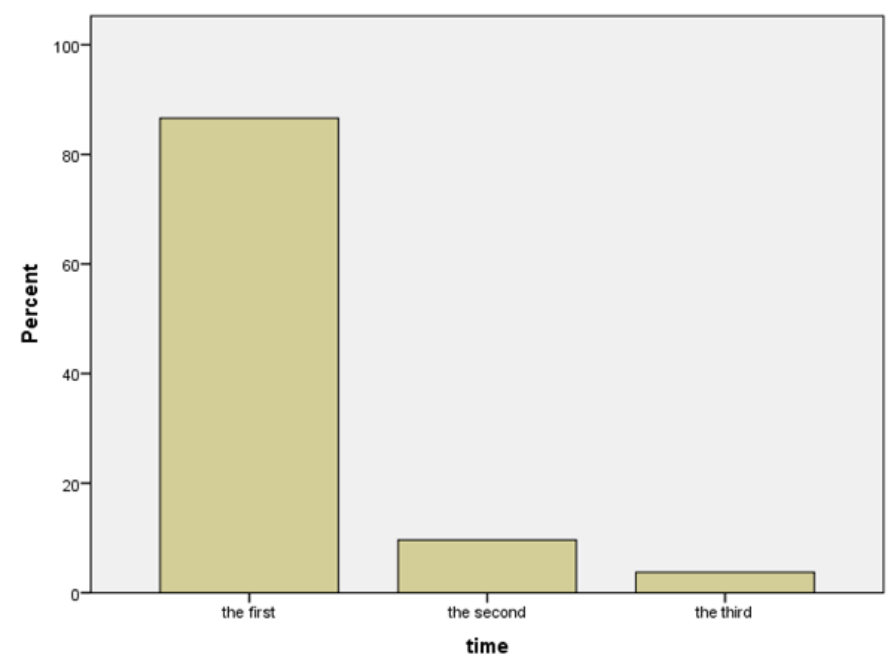

Figure 3. Quantitative and percentage data of PERH on the first, second and third minutes percentage terms) in $86 \%$ (853), at the 2 nd minute in $9.4 \%$ (95) and at the 3 rd minute in $3.8 \%$ (37) of the subjects.

Three types of pathologic reaction to hyperventilation (PERH) have been revealed: Type 1 reaction (PERH-1) $-73.1 \% / 720)$ consists 
in the disorganization of the basal rhythm, which is manifested in the development of insufficiently regular alpha activity of high amplitude and mean index as well as of individual theta and delta waves without paroxysmal reaction (Figure 4, Table 4).

Type 2 reaction (PERH-2) $2-23.2 \% / 229$ subjects) develops in the form of generalized, high-amplitude, monomorphic or polymorphic slow-wave synchronous paroxysmal discharge without epileptiform Elements (Figure 4, Table 4).

Type 3 reaction (PERH-3) - 3.7\%/36 subjects) causes epileptiform activity both in the form of generalized paroxysmal discharge and as separate grapho-elements (sharp waves, single spikes, and spike-wave complexes) (Figure 4, Table 4).

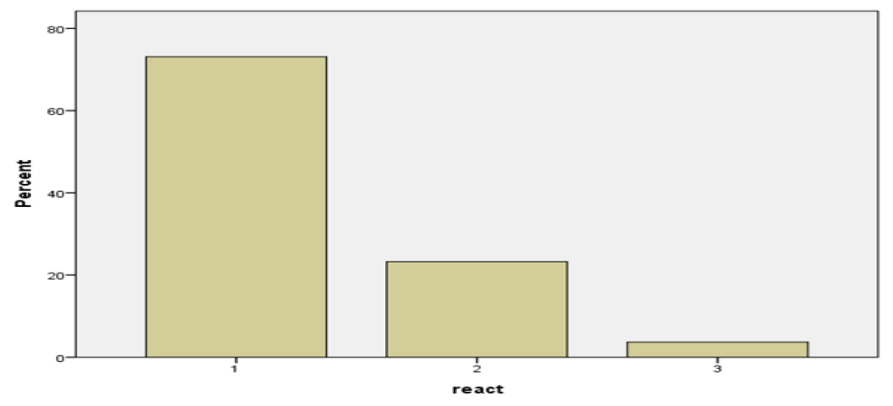

Figure 4. The quantitative and percentage indicators of a particular type of PERH

Table 1. Quantitative and percentage data of individuals with pathological EEG-reactions on hyperventilation (PERH) in different age groups

\begin{tabular}{|c|c|c|c|c|c|}
\hline \multicolumn{2}{|c|}{ Age } & Frequency & Percent & Valid Percent & Cumulative Percent \\
\hline \multirow{4}{*}{ Value } & $3-6$ & 130 & 13.2 & 13.2 & 13.2 \\
\cline { 2 - 6 } & $7-12$ & 264 & 26.8 & 26.8 & 40.0 \\
\cline { 2 - 6 } & $13-18$ & 167 & 17.0 & 17.0 & 57.0 \\
\cline { 2 - 6 } & $19-30$ & 163 & 16.5 & 16.5 & 73.5 \\
\cline { 2 - 6 } & $31-50$ & 175 & 17.8 & 17.8 & 91.3 \\
\cline { 2 - 6 } & 50 more & 86 & 8.7 & 8.7 & 100.0 \\
\cline { 2 - 6 } & Total & 985 & 100.0 & 100.0 & \\
\hline
\end{tabular}

Table 2. Quantitative and percentage data of subjects with PERH according to gender

\begin{tabular}{|c|c|c|c|c|c|}
\hline \multicolumn{2}{|c|}{ Sex } & Frequency & Percent & Valid Percent & $\begin{array}{c}\text { Cumulative } \\
\text { Percent }\end{array}$ \\
\hline \multirow{3}{*}{ Value } & Male & 432 & 43.9 & 43.9 & 43.9 \\
\cline { 2 - 6 } & Female & 553 & 56.1 & 56.1 & 100.0 \\
\cline { 2 - 6 } & Total & 985 & 100.0 & 100.0 & \\
\hline
\end{tabular}

Table 3. Quantitative and percentage data of PERH on the first, second and third minutes

\begin{tabular}{|c|c|c|c|c|c|}
\hline \multicolumn{2}{|c|}{ Time } & Frequency & Percent & Valid Percent & $\begin{array}{c}\text { Cumulative } \\
\text { Percent }\end{array}$ \\
\hline \multirow{3}{*}{ Value } & First & 853 & 86.6 & 86.6 & 86.6 \\
\cline { 2 - 6 } & Second & 95 & 9.6 & 9.6 & 96.2 \\
\cline { 2 - 6 } & Third & 37 & 3.8 & 3.8 & 100.0 \\
\cline { 2 - 6 } & Total & 985 & 100.0 & 100.0 & \\
\hline
\end{tabular}

Table 4. The quantitative and percentage indicators of a particular type of PERH

\begin{tabular}{|c|c|c|c|c|c|}
\hline React & Type & Frequency & Percent & $\begin{array}{c}\text { Valid } \\
\text { Percent }\end{array}$ & $\begin{array}{c}\text { Cumulative } \\
\text { Percent }\end{array}$ \\
\hline \multirow{4}{*}{ Value } & 1 & 720 & 73.1 & 73.1 & 73.1 \\
\hline & 2 & 229 & 23.2 & 23.2 & 96.3 \\
\hline & 3 & 36 & 3.7 & 3.7 & 100.0 \\
\hline & Total & 985 & 100.0 & 100.0 & \\
\hline
\end{tabular}

\section{Discussion}

The results of the study have shown two types of the response to hyperventilation: normal (55\%) and pathologic (45\%), which was also described by other $[18,19]$. The normal reaction(response) consists in a diffuse deceleration of the basic/baseline rhythmicity of the EEG: the revealed slow- wave activity (capable of inducing EEG synchronization) is referred to as hyperventilation synchronization which is considered as a norm in all age groups [20] It should be noted that a prerequisite for asserting a normal physiologic response to hyperventilation is a rapid restoration of the background rhythm within one minute after the termination of the test [20,21]. An EEG recorded without changes in response to hyperventilation is a physiological reaction which is also considered the norm [12,22]. In the current study both types of responses (the norm) made up 55\% of the total contingent.

Different types of abnormal (pathologic) EEG reactions to hyperventilation are problematic for the interpretation [10,11]. The mechanisms of alterations in hyperventilation-induced EEG, particularly with high-amplitude slow-wave activity (paroxysmal synchronization) have not been completely clarified.

There is an assumption [23], that the cause of the development of slow waves is the impairment of cerebral circulation due to hypocapnia and associated acute alkalosis [24] which results in insufficient oxygen and glucose supply to the brain.

The data regarding the influence of carbonic acid on EEG (in normal respiration) are controversial. Carbonic acid acts on the brain potential both through humoral and reflex way by means of the of blood vessel chemoreceptors $[14,15]$, which causes the excitement of the brain stem reticular formation. This, in turn, leads to the modulating influence on the cerebral cortex (arousal, EEG desynchronization).

Regarding the origin of the EEG alterations revealed at forced breathing, these events seem urgent and require further investigation. Hypocapnia that develops in response to hyperventilation causes the deactivation of the brain reticular structure [25], which is manifested on the EEGs by the following changes: dysrhythtmia, hypersynchronization, different types of slow-wave and paroxysmal activity (with or without epileptic seizure). These patterns of pathologic EEG responses were observed in 985 subjects.

Based on the preliminary data, it is obvious that the three types of responses to hyperventilation PERH are mostly observed at the first minute of functional loading while restoration of the background rhythmicity occurs 2 or more minutes after the termination of the test $[20,21]$.These findings are consistent with the data of other authors $[11,26]$ whose note that EEG changes are observed at the beginning of forced breathing at the first minutes of hyperventilation. Accordingly, the prolongation of the experiment for another 2 minutes is inadvisable and especially dangerous for children.

To a certain extent, the explanation of the processes occurring in the brain at the background of (during) hyperventilation was given above and can be imagined (interpreted) as follows: the fall/ drop of the partial pressure of carbon dioxide causes hypocapnia and subsequent vasoconstriction followed by cerebral ischemic anoxia. The concurrently developing respiratory alkalosis is accompanied by the shift (change) in oxygen dissociation curve (Bohr effect) and a decrease in ionized $\mathrm{Ca}^{++}$[12]. Presumably, such a complex of changes causes deceleration of the EEG. It should be mentioned that this hypothesis has a significant drawback: the partial pressure of carbon 
dioxide reduces to a minimum 1.5-2 minutes after the beginning of the experiment, while changes in EEG (paroxysmal EEG synchronization and/or generalized epileptiform discharges) are revealed) with the onset of forced breathing. Such incompatibility in time of the events considered makes it necessary to search for alternative mechanisms that may more adequately explain the deceleration of the EEG baseline rhythm from the first minutes of hyperventilation and the causes of enhanced epileptogenesis.

The reasonable is to consider a set of views developed by "hormesis theory". In particular, it studies the mechanisms of weak stressorstimulated effects on the body at an early stage of action.

The term hormesis was introduced in 1943 by C. Southam and J. Ehrlich, [27], however this theory has received special attention and definite scientific recognition in the last two decades [27-30]. Hormesis represents a paradoxical stimulation, i.e. low doses (intensity) of different substances and factors cause positive influence on the organism, while high doses of these substances are harmful $[31,32]$. The main agents of hormesis are: different types of radiation, effects of temperature, heavy metals and some drugs, as well as a short- term exposure of cells and the whole organism to chemical, physical or psychological (stress) impacts. Presumably, hyperventilation causes low stress which may stimulate the appearance of PERH at the beginning of forced breathing. Particularly, the detection of pathologic EEG developing at the first minutes of hyperventilation is probably associated with the effect of hormesis. This view is supported by the following consideration: respiration is the exception of autonomic function that is controlled voluntary. Any person can stop or start breathing faster. This is possible because the respiratory function is controlled by both autonomic and somatic nervous systems. The Respiratory System, due to these particular features becomes especially sensible to different factors (stress, fear, overwork) affecting psycho-somatic, nervous and psychic spheres of the organism. At that, it should be taken into account that individual specificity of PERH (occurrence, detection time and degree during functional loading) may be conditioned by the individual sensitivity of the subjects to a mild stress and a decrease in partial pressure of carbon dioxide. Based on all of the above, it is not easy to distinguish which of the impacts is paramount, determinative and/or particularly significant. This, in turn, makes it difficult to interpret every single pathologic EEG response to hyperventilation, which necessitates the extension of (further) studies.

\section{Conclusion}

1. Three types of pathological EEG reaction to hypoventilation have been revealed: disorganization of baseline rhythmicity, generalized, high-amplitude, monomorphic or polymorphic slow-wave paroxysmal discharges and epileptiform activity.

2. Pathological reactions to hyperventilation are predominantly revealed at the first minute of loading, which is diagnostically informative. Therefore the extension of functional loading is not advisable/ recommendable, especially in patients with different disorders and in children.

3. The appearance of pathological EEG reactions/responses to hyperventilation could not be explained only based on hypocapnia, due to it develops later on. We think it reasonable to consider a set of views developed by "hormesis " theory. In particular, the stimulating effects of low stress on the body in/at the early stages of their impact.

\section{References}

1. Binnie CD, Stefan H (1999) Modern electroencephalography: its role in epilepsy management. Clin Neurophysiol 110: 1671-1697.

2. Kane N, Grocott L, Kandler R, Lawrence S, Pang C (2014) Hyperventilation during electroencephalography: safety and efficacy. Seizure 23: 129-134.

3. Mendez OE, Brenner RP (2006) Increasing the yield of EEG. J Clin Neurophysiol 23: 282-293.

4. Fisch B (2006) Fisch and Spehlmann's EEG primer Basic principles of digital and analog EEG. Elsevier, Germany pp: 7-12, 621 .

5. Niedermeyer E, Lopes de Sylva F (2005) In: Electroencephalography: basic principles, clinical applications and related fields. Lopes de Sylva F (ed) Lippincott Williams \& Wilkins, Philadelphia, USA pp: 684-687.

6. Angus-Leppan H (2007) Seizures and adverse events during routine scalp electroencephalography: a clinical and EEG analysis of 1000 records. Clin Neurophysiol 118: 22-30.

7. Yenjun S, Harvey AS, Marini C, Newton MR, King MA, et al. (2003) EEG in adultonset idiopathic generalized epilepsy. Epilepsia 44: 252-256.

8. Adams DJ, Lueders H (1981) Hyperventilation and 6-hour EEG recording in evaluation of absence Seizures. Neurology 31: 1175-1177.

9. Craciun L, Varga ET, Mindruta I, Meritam P, Horváth Z, et al. (2015) Diagnostic yield of five minutes compared to three minutes hyperventilation during electroencephalography. Seizure 30: 90-92.

10. Guaranha MS, Garzon E, Buchpiguel CA, Tazima S, Yacubian EM, et al. (2005) Hyperventilation revisited: Physiological effects and efficacy on focal seizure activation in the era of video-EEG monitoring. Epilepsia 46: 69-75.

11. Glukhova L, Mukhin K, Nikitina M, Barletova E, Tupikova E (2013) The importance of electroencephalographic activating methods in clinical practice of neurologist. Russ J Child Neurol 8: 15-30

12. www. neuronet.ru/bibliot/b002/hv. html

13. Hayashi K, Fujikawa M, Sawa T (2008) Hyperventilation-induced hypocapnia changes the pattern of electroencephalographic bicoherence growth during sevoflurane anaesthesia. Br J Anaesth 101: 666-672.

14. Brian JE (1998) Carbon dioxide and the cerebral circulation. Anesthesiology 88: 1365 1386.

15. https://www.liverpool.ac.uk/ gdwill/hons/gul_lect.pdf

16. www.psychologicalharassment.com/acidbase-balance.html

17. https://nirvana.fitness/breath-control-regulation-of-respiration-o2-vs-co2-20-10-2015. html

18. Siddiqui SR, Zafar A, Khan FS, Shaheen M (2011) Effect of hyperventilation on electroencephalographic activity. JPMA 61: 850 .

19. Srinivasulu N, Shashikala K, Srinivasa R (2014) Nonspecific abnormal EEG patterns during hyperventilation test on the electroencephalogram of normal and epileptic patients. RRJMHS 3: 92-97

20. Fish B and Elson L (2003) Activation methods Current practice of clinica electroencephalography. Ebersole JS, Pedley TA (eds) Lippincott Williams \& Wilkins, Philadelphia, USA pp: 246-270.

21. Blagosklonova NK (2000) In: Clinical electroencephalography, (in Epileptology of childhood) Manual for doctors. Petrukhin M (ed) pp: 309-406.

22. Fisher R (2011) In: The Johns Hopkins Atlas of Digital EEG. Kraus G, Kaplan P (ed) The Johns Hopkins University press, Maryland, United States pp: 711-761.

23. Van der Worp HB, Kraaier V, Wieneke GH, Van Huffelen AC (1991) Quantitative EEG during progressive hypocarbia and hypoxia. Hyperventilation-induced EEG changes reconsidered. Electroencephalogr Clin Neurophysiol 79: 335-341.

24. Morrison V, Chesnokova N, Bizenkova M (2015) Typical violations of the acid-alkaline state. Int J App Fund Res 3: 273-278

25. Son S, Kwon OY, Jung S, Kim YS, Kim SK, et al. (2012) Relationship between hyperventilation-induced electroencephalographic changes and $\mathrm{PCO}_{2}$ level. $J$ Epilepsy Res 2: 5.

26. Litchfield P (2008) The Brain-Breath Connection: Breathing Chemistry and its Effects on Neurophysiology, Emotion, Cognition, Personality, performance and Health https:// www.futurehealth.org. 
27. Calabrese EJ (2008) Dose-response features of neuroprotective agents: an integrative summary. Crit Rev Toxicol 38: 253-348.

28. Calabrese EJ (2016) Preconditioning is hormesis part I: Documentation, dose-response features and mechanistic foundations. Pharmacol Res 110: 242-264.

29. Calabrese V, Cornelius C, Cuzzocrea S, Iavicoli I, Rizzarelli E, et al. (2011) Hormesis, cellular stress response and vitagenes as critical determinants in aging and longevity. Mol Aspects Med 32: 279-304.
30. Calabrese V, Giordano J, Crupi R, Di Paola R, Ruggieri M, et al. (2017) Hormesis, cellular stress response and neuroinflammation in schizophrenia: early onset versus late onset state. J Neurosci Res 95: 1182-1193.

31. Murado MA, Vázquez JA (2007) The notion of hormesis and the dose-response theory: a unified approach. $J$ Theor Biol 244: 489-499.

32. Yoshimasu T, Ohashi T, Oura S, Kokawa Y, Kawago M, et al. (2015) A theoretical model for the hormetic dose-response curve for anticancer agents. Anticancer Res 35: $5851-5855$.

Copyright: (C2020 Khachidze I. This is an open-access article distributed under the terms of the Creative Commons Attribution License, which permits unrestricted use, distribution, and reproduction in any medium, provided the original author and source are credited. 